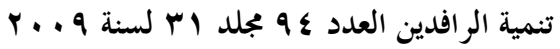

$$
\begin{aligned}
& \text { كلية الإدارة والاقتصاد -جامعة الموصل } \\
& \text { ص ص[rV.-ror } \\
& \text { تطبيق نموذج تسعير الموجود الر أسمالي في سوق الأوراق } \\
& \text { المالية في الكويت الزوديث } \\
& \text { الدكور سرمد وكب الميليل } \\
& \text { استاذ-قسم العلوم المالية والمصرفية } \\
& \text { كلية الادارة والاقتصاد-جامعة الموصل }
\end{aligned}
$$

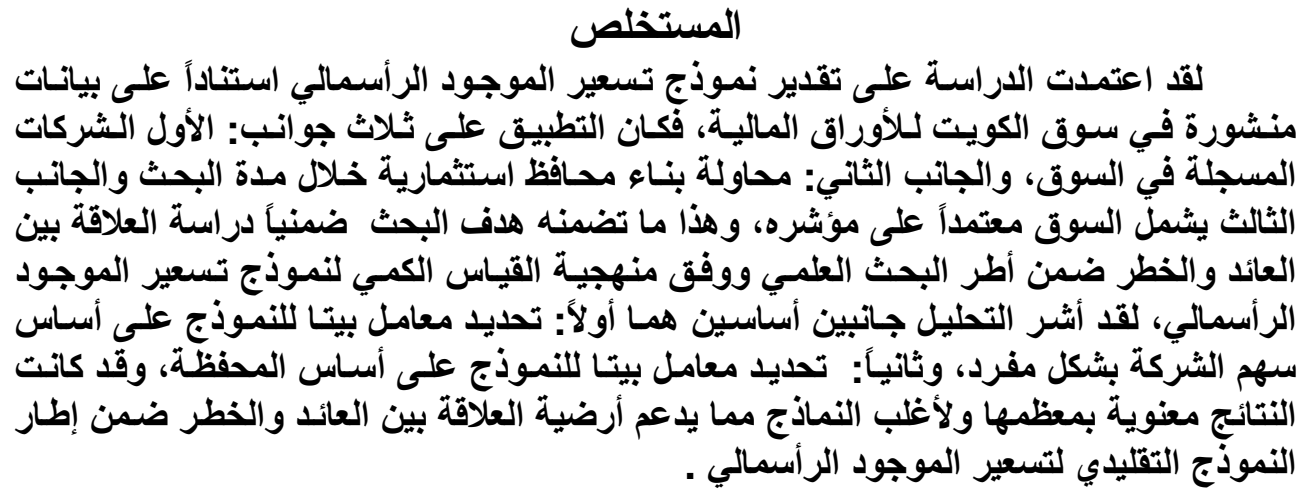

\title{
Application of Capital Asset Pricing Model in ALKWAIT Capital Market
}

\author{
Sarmad K. Al-Jameel (PhD) \\ Professor \\ Department of Finance and Banking \\ University of Mosul
}

\begin{abstract}
This research used the actual data of ALKWAIT capital market in estimating the capital asset pricing model. The application has three sides: the first one covered all companies listed in the market and the second side focused on the portfolios building during the research period, whereas the third took the market indices. However, this is the implication of the research objective which is studying the relationship between return and risk under the methodology of the capital asset pricing model. The research analysis indicated two important issues, the determination of beta coefficient for individual stock and for the portfolios. The result is significant in different levels of probability within the traditional capital asset pricing model.
\end{abstract}




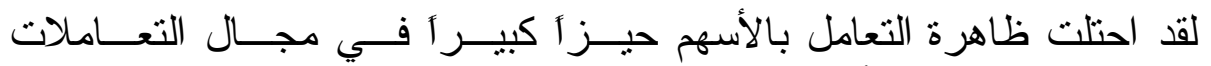

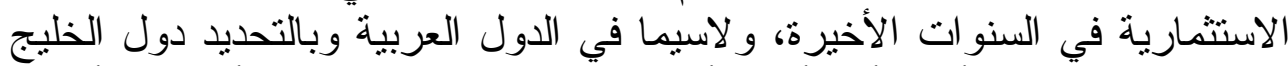

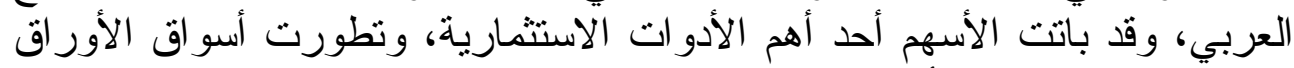

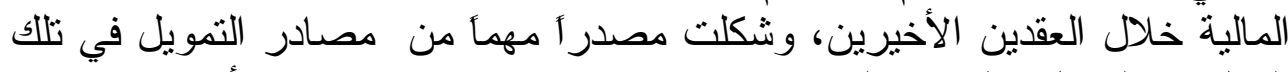

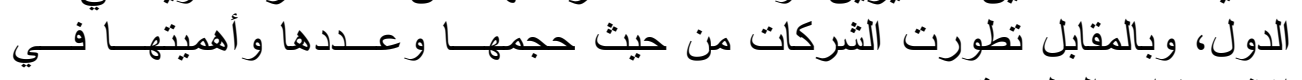
الاقتصادات الخليجية.

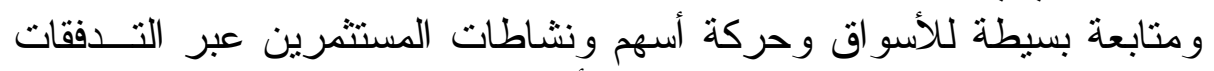

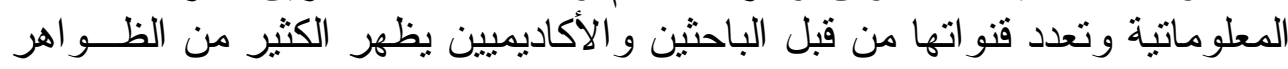

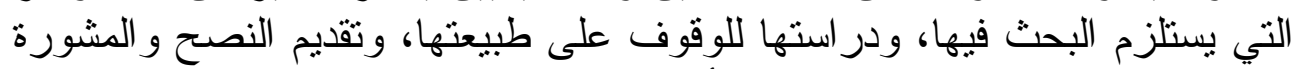

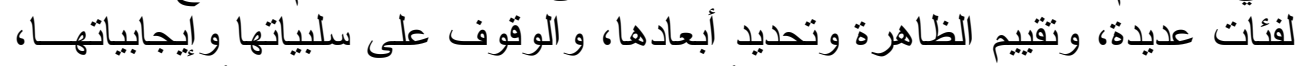

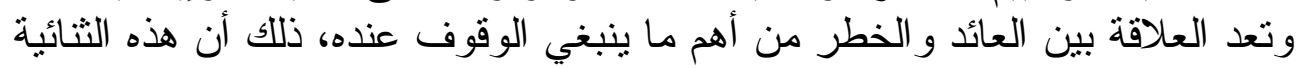

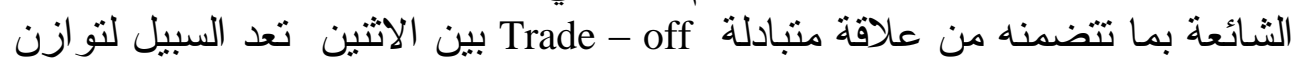

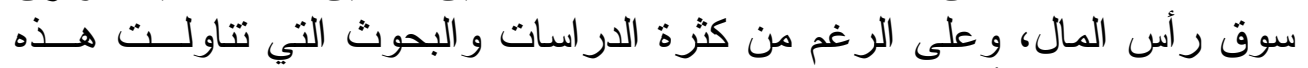

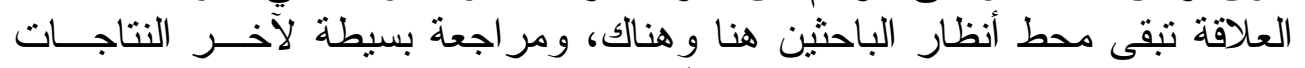

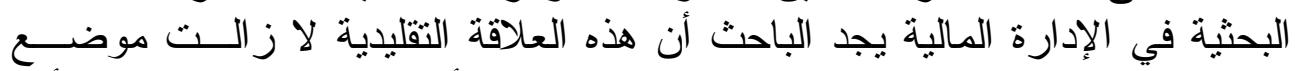

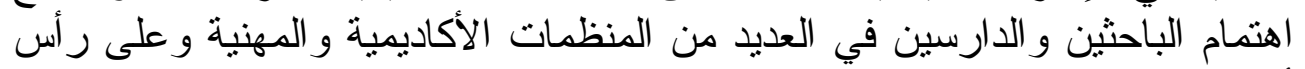
أسبقيات العناوين التي تعنى بالاستثمار . لإنين

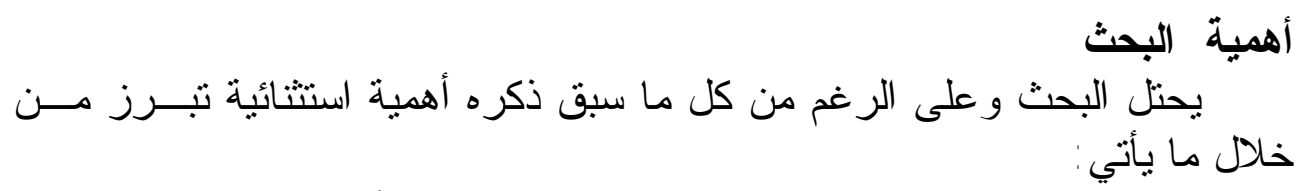

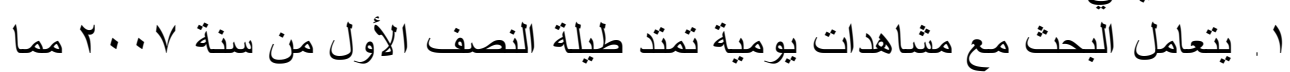

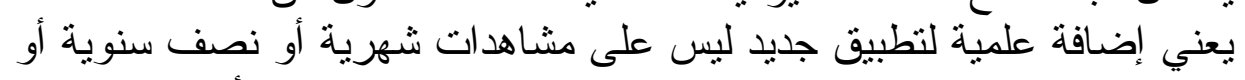

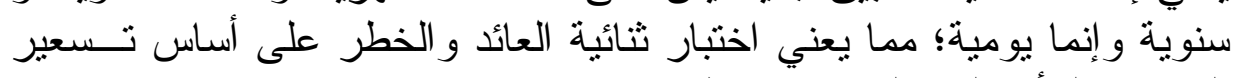

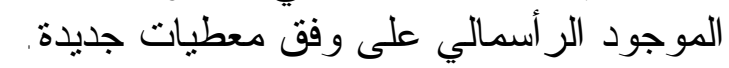

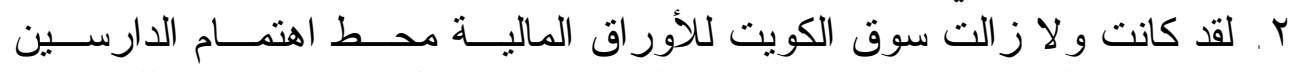

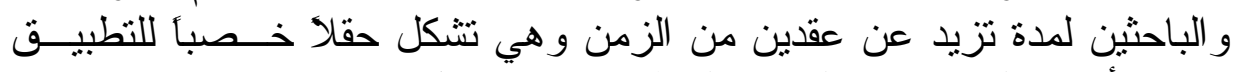

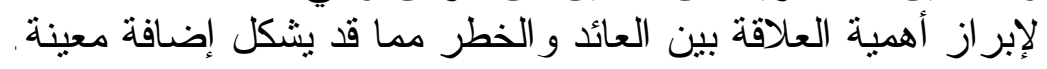

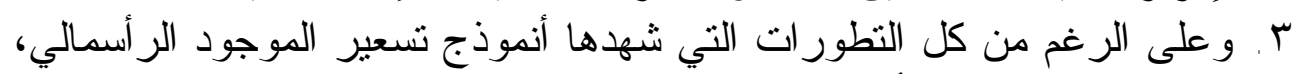

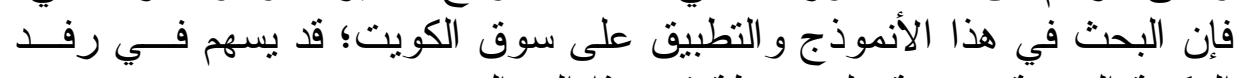
المكتبة العربية بجزئية ولو بسيطة في هذان ولئية المجال . 


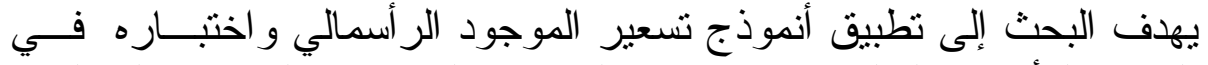

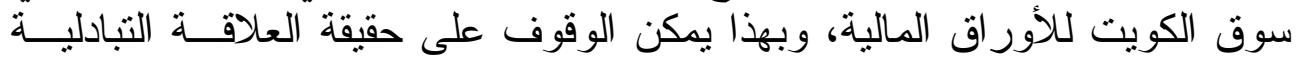

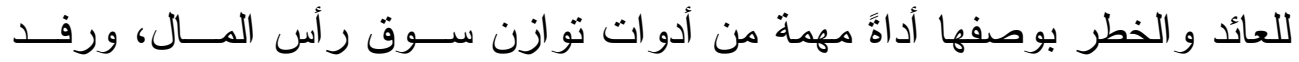
المستثر الكويتي بطبيعة تللك العلاقة ومستقبلها.

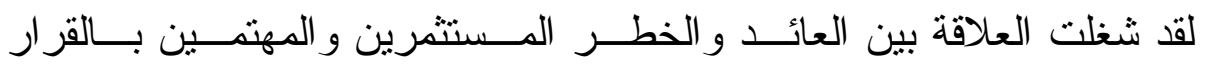
فرضيات البحث

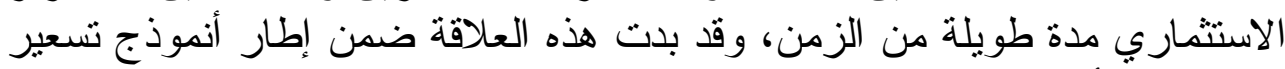

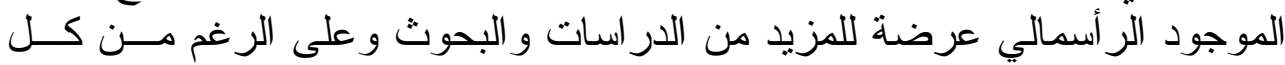

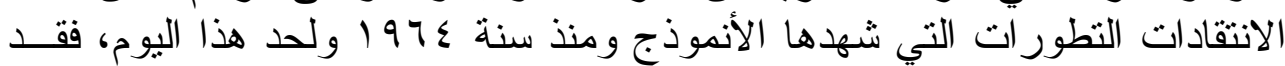

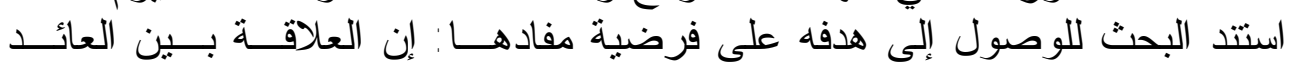

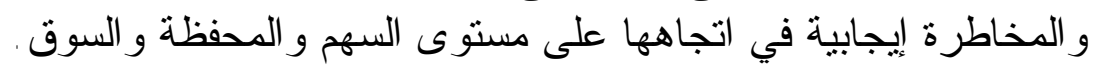

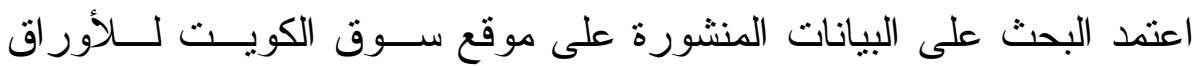
بيانات البحث و أدواته

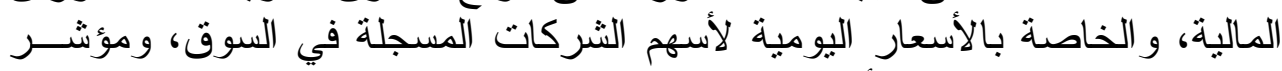

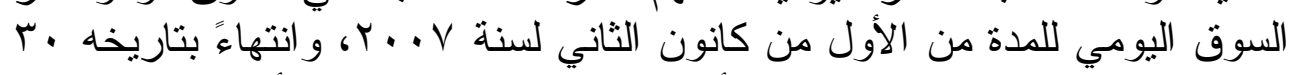

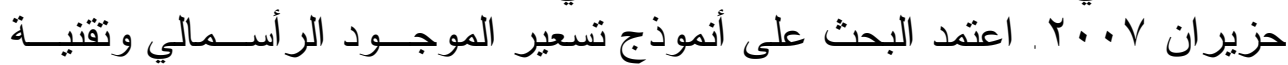
المحفظة في اختبار بيانات البحث بهدف اعثى تحقيق الأهداف.

أولاً - الأسس النظرية لأموذج تسعير الموجود الرأسمالي ومر اجعة لأدبياته

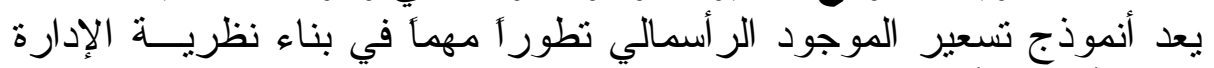

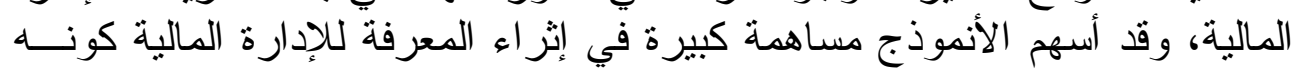

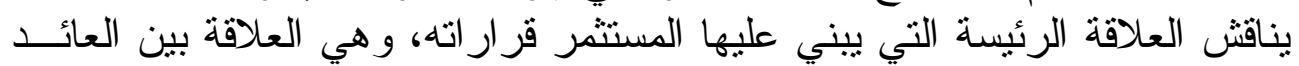

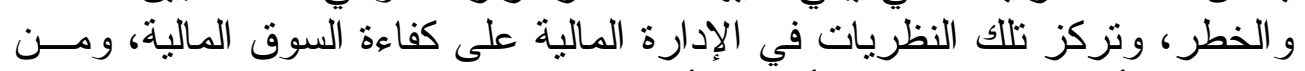

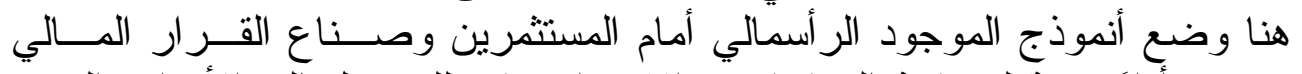

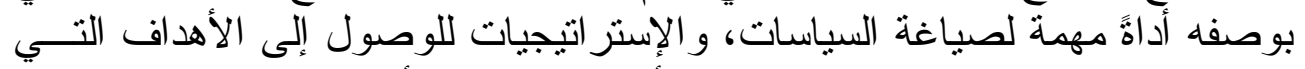

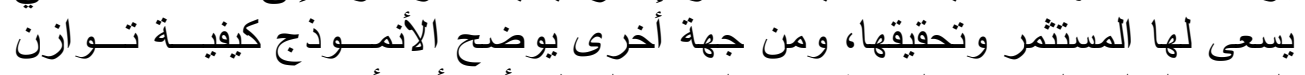

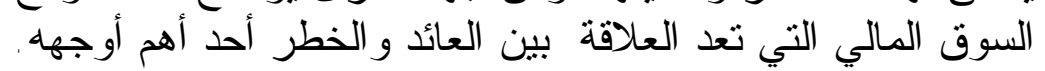

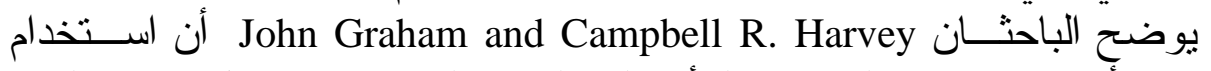
الثركات لأنموذج تسعير الموجود الثران أسمالي القائم على تحديد معامل بيتا، و العائد

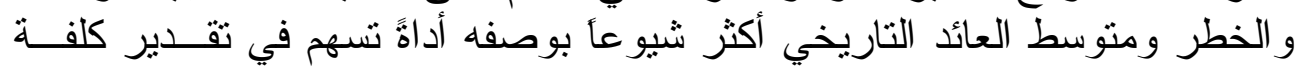

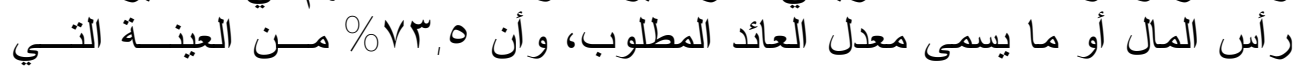

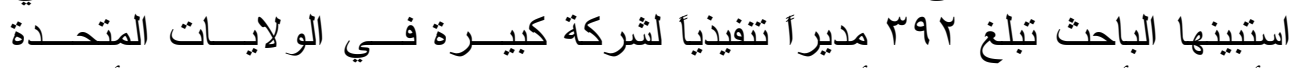

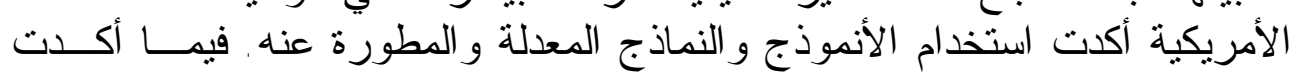




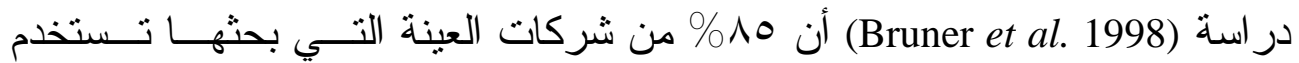

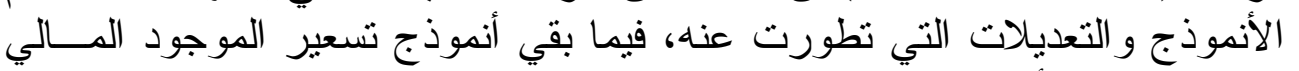

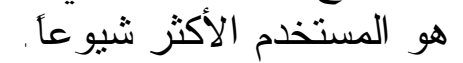

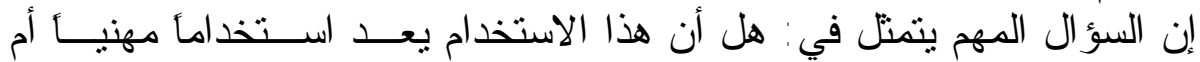

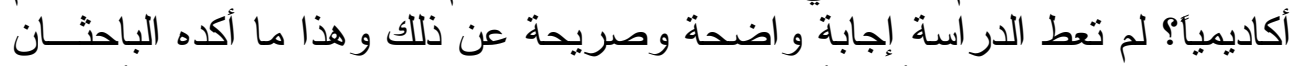
Fama and French, (Fama and French, 1992, 427-465)

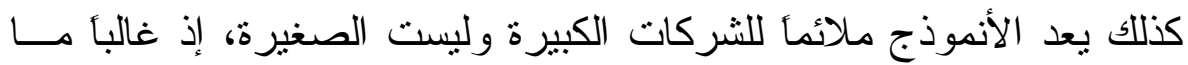

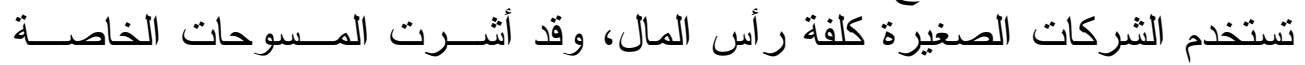

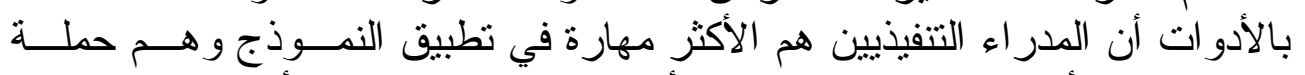

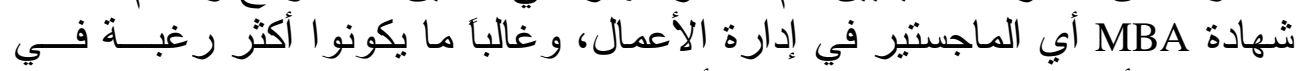

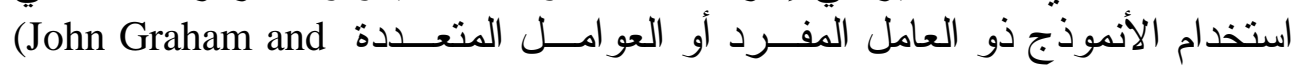
.Campbell R. Harvey, 2001, 203-204) يعد أنموذج تسعير الموجود الر أسمالي بمثابة النظرية الأساس التي تقوم على التى

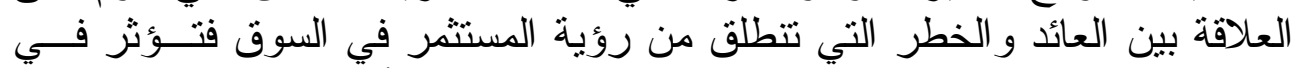

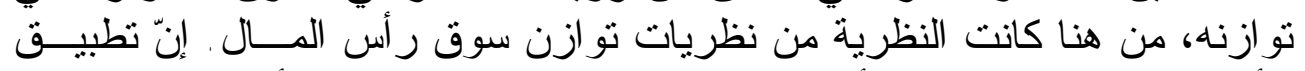

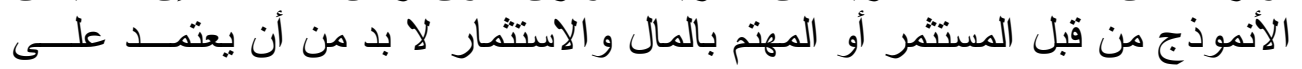

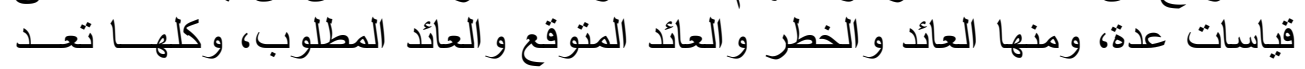

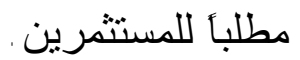

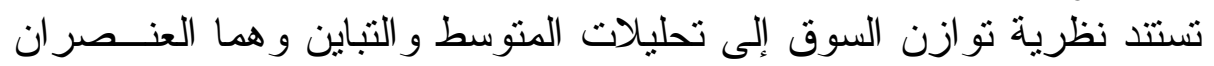

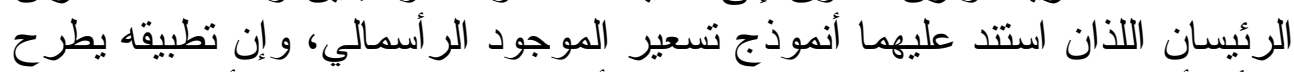

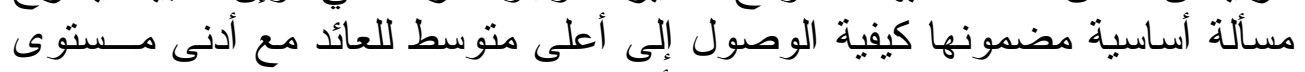

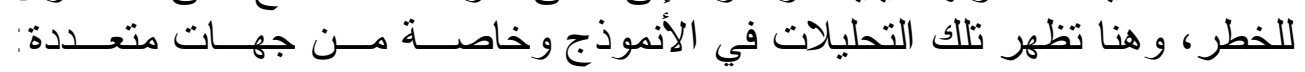

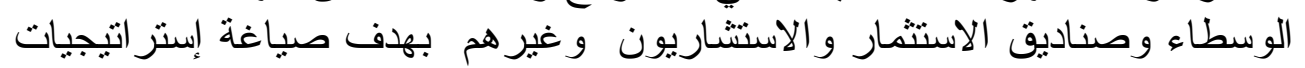

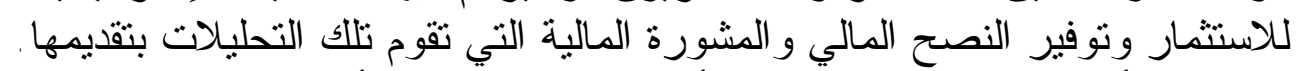

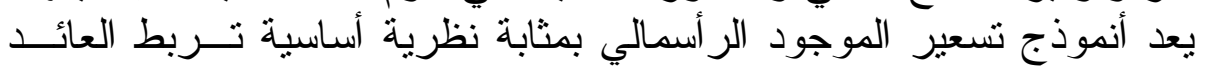

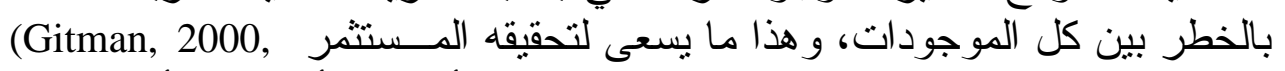

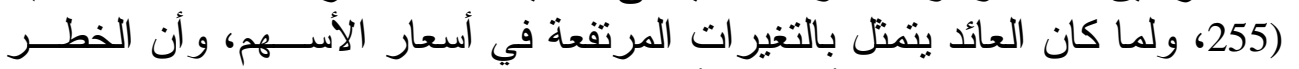

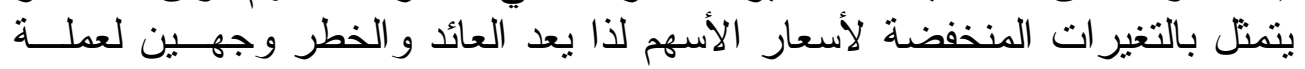

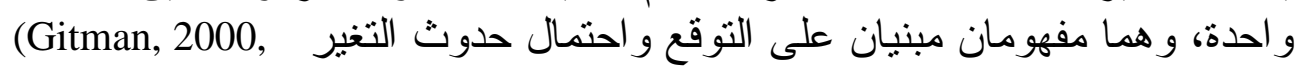

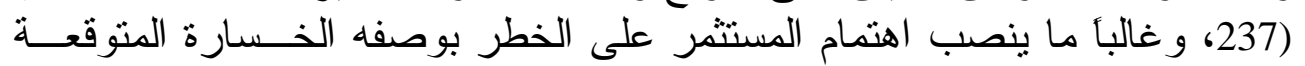

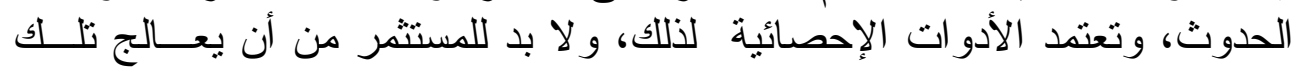

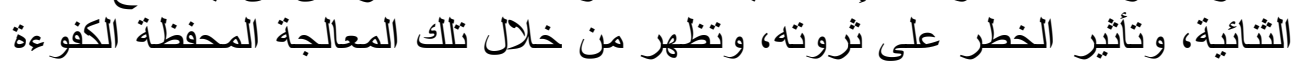
بوصفها أداةً لتحقيق تعظيم العائد وتقليل الخطر و وعلى وفن من معطيات معينة . 
يستتد نموذج تسعير الموجود الر أسمالي على افتر اضات غالباً مــا تناقـشها

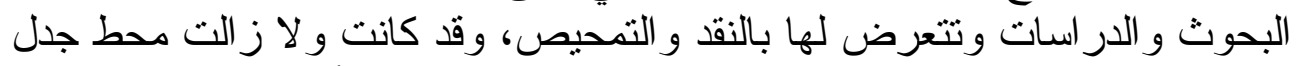

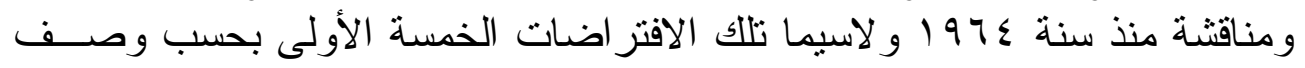
Bill Rees

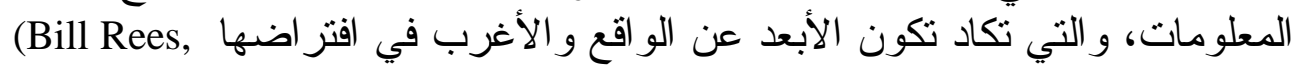
.1990, 225)

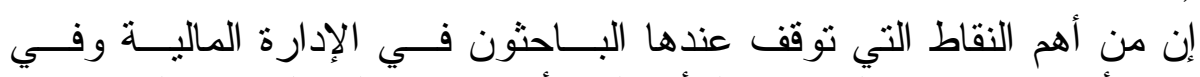

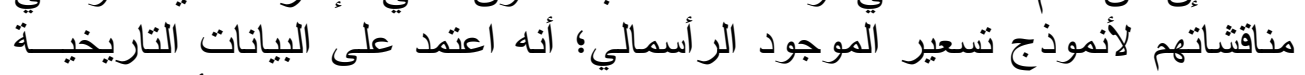

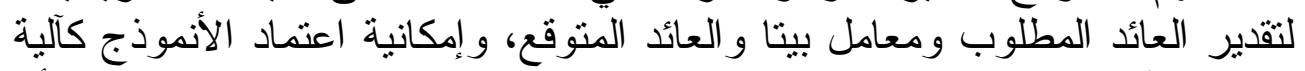

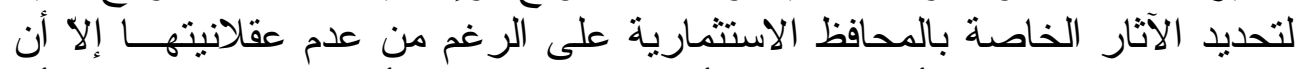

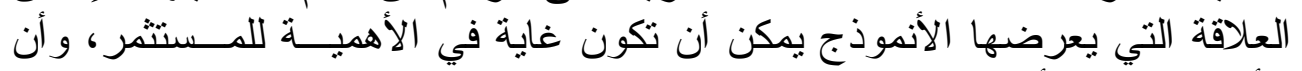

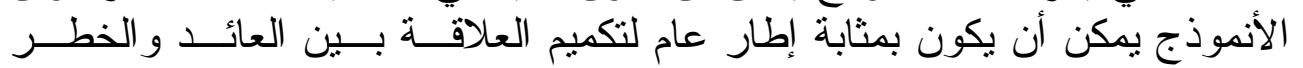

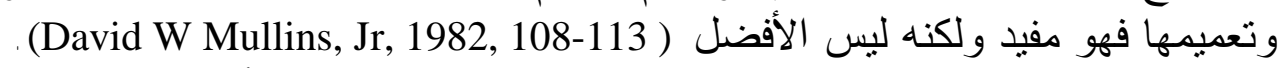

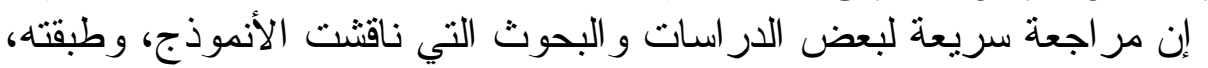

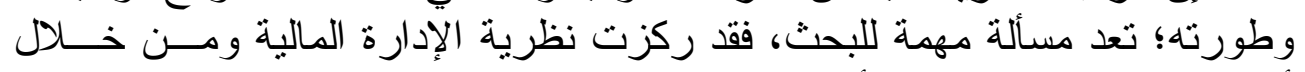

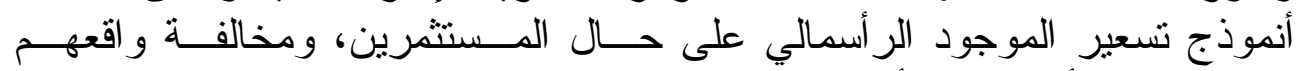

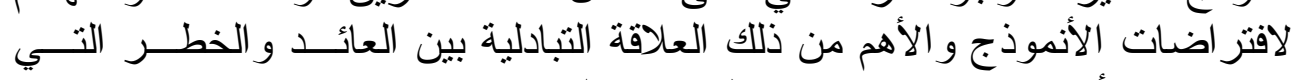

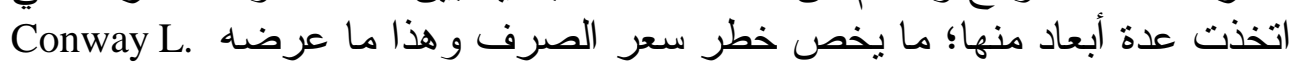
Lackman, 1990

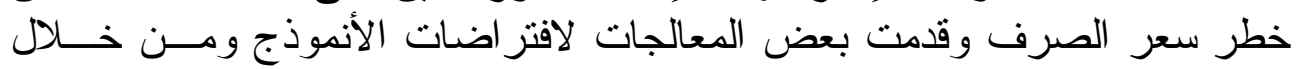

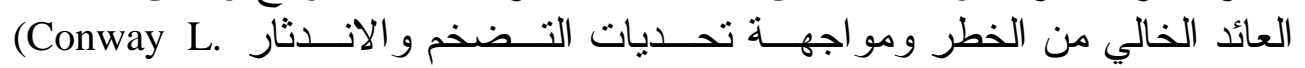
. Lackman, 1990,1)

Chatterjee, Sayan, Lubertkin Michael H. Schuize, ونــاقش البــاحثثن الاتجاه الإستر اتيجي في الإدارة المالية، وما فرضه الأنموذج من William, 1999

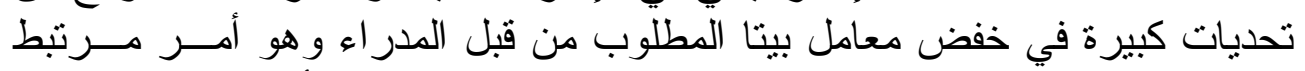

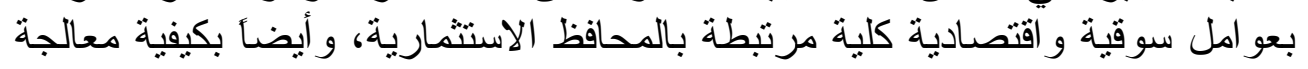

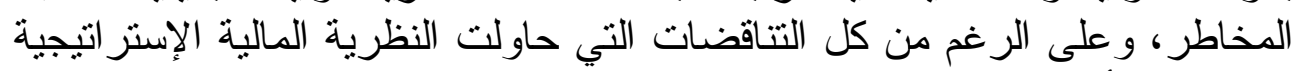

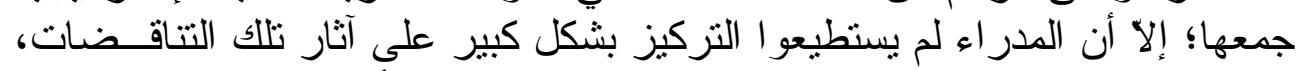

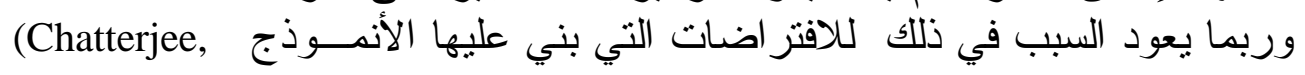
.Sayan, Lubertkin Michael H. Schuize, William, 1999 )

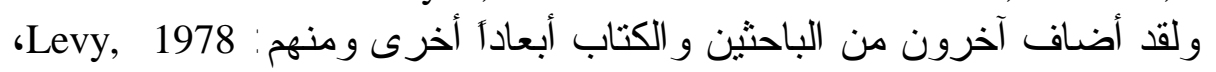

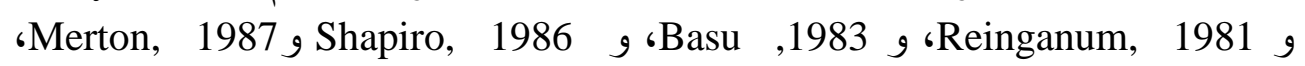
Fama and ،Fama 1991, 1997 و 1991 و Chan Hamao and Lakonishok m 1981 و (Nick Durack, Robert B.Durand, Ross A. French 1992, 1993, 1995, 1996

Maller, 2004, 139-162) 


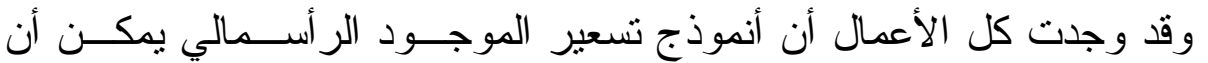

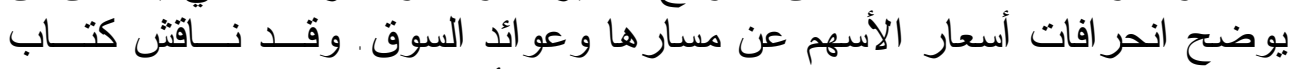
آخرون الموضو ع من خلال استخدام بيتا المتعدد الأغر اض في الأن النموذج ومنهم: و Fama Robert, 1993 (John Graham and Campbell R. Harvey, 2001) Pettengill and Sundaram and Mathur, g ‘Bhardwaj and Brooks m 1993 Howton and Peterson 1998 ، و 1995 وقد أكد الباحثون العلاقة الر اسخة و المعنوية بين العائد المتوقع ومعامل بيتــــا

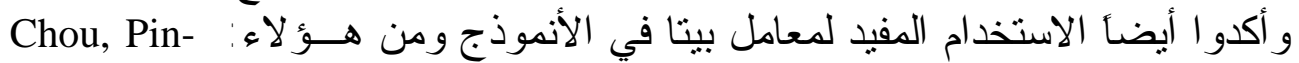

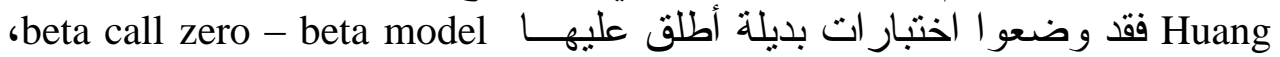
وتعد هذه التطور ات في الاختبار ات الأدائية للنموذج نقطة تغير كبير فـي مسسار الأنموذج وقد أسهر كتاب آخرون ومنهر :

Chen, Shimin, Dodd, James L. ،Jagannathan, Ravi, Meier, Iwan, 2002 2002 Grigoris Michailidis, Stavrous, Tospogllou, Demetrios Pahastaslon and Eleni Mariola, 2006.

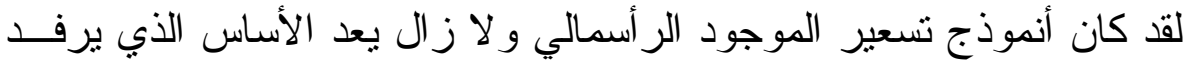

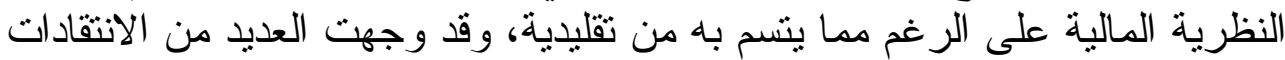

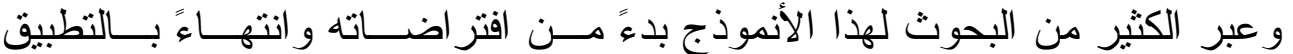

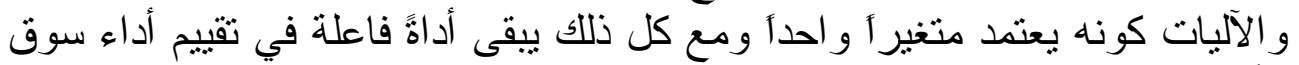

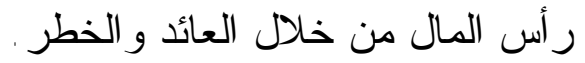

\section{ثانياً - المنهجية وتوصيف البيانات} خطوات تطبيق أنموذج تسعير الموجود الرئيات أسمالي وقياس المتغيرات

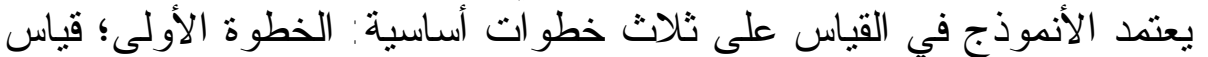

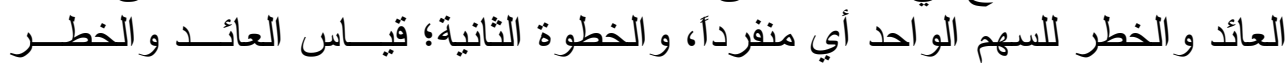

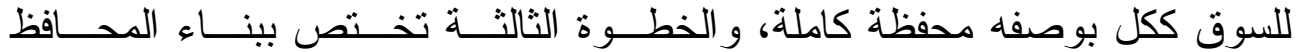
الاستثمارية على وفق معطيات أنموذج نسعير الموجود الر أسمالي.

تم تحديد متغير ات الأنموذج وكما يأتي:

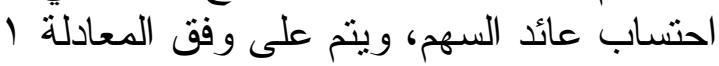

$$
R_{t}=\frac{p_{t}-p_{t-1}+C_{t}}{p_{t-1}}
$$

$R_{t}=$

سعر السهر

توزيع الأرباح النقدية 


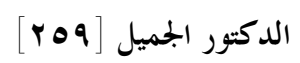

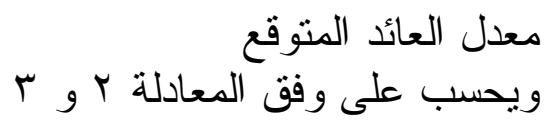

$\bar{R}=\sum_{t=1}^{n} R_{i} \times p r_{i} \ldots \ldots .2$

$\bar{R}=$ معدل العائد المتوقع

$R_{i}=$ معدل العائد للسهر

احتمال الحدوث

$\bar{R}=\frac{\sum_{t=1}^{n} R_{i}}{n} \ldots .3$

عدد الأسهر

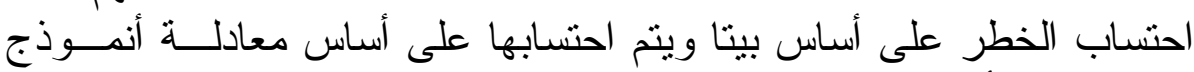

تسعير الموجود الر أسمالي المعادلة ع

$R_{i}=R_{F}+\left[b_{i} \times\left(R_{m}-R_{F}\right)\right] \quad \ldots 4$

$R_{F}=$ معدل العائد الخالي من المخاطرة

$R_{m}=$ معدل عائد السوق السوة

معل معل بيتا

احتساب معدل العائد المتوقع للمحفظة ...

$R_{p}=\sum_{i=1}^{n} w_{i} \times R_{i} \ldots .5$

النسبة من مجموع المحفظة للسهم

$R_{p}=$ معدل عائد المحفظة عة لمهة

قياس أنموذج تسعير الموجود الر أسمالي للمحفظة

بتم قياس بيتا المحفظة كما في المعادلة ....

$b_{p}=\sum_{i=1}^{n} w_{i} \times b_{i} \ldots 6$

معامل بيتا المحفظة = معام

معامل بيتا السهم

$\bar{R}-R_{F}=\beta\left(\bar{R}_{M}-R_{F}\right) \ldots . .7$

معدل العائد المتوقع

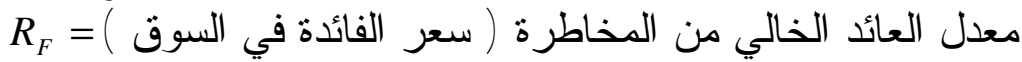

$\beta=$ معامل بيتا للسهر 


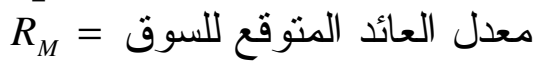

Grigoris Michailidis, Stavrous, Tospogllou, Demetrios Pahastaslon and Eleni Mariola, 2006.

Buckley ,Ross, Westerfield and Jaffe, 1998, 238-275.

\section{توصيف البيانات}

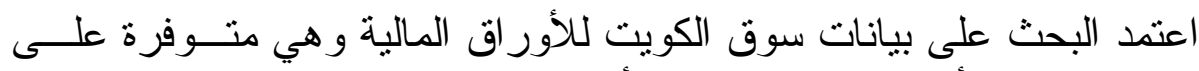

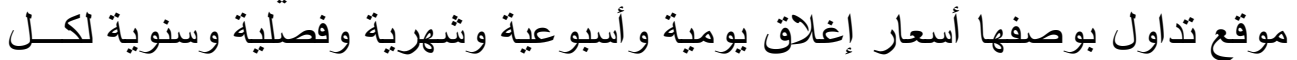

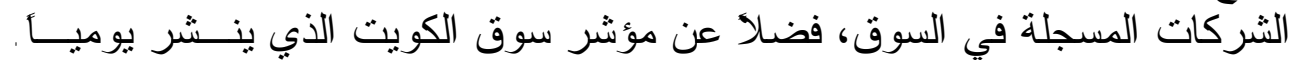

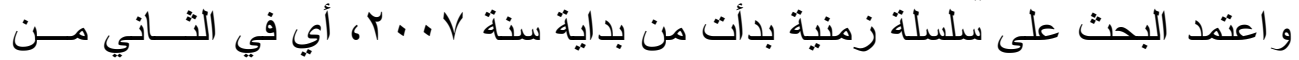

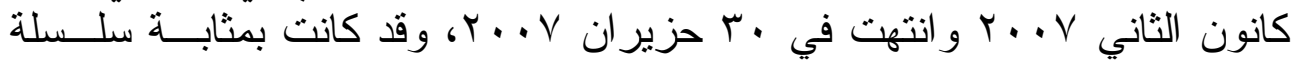

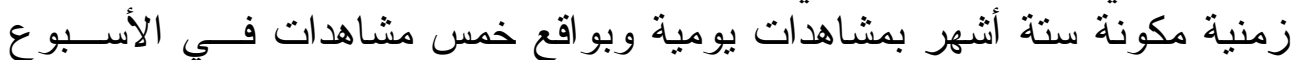

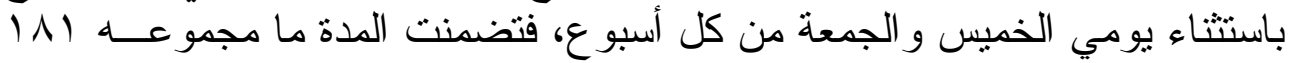

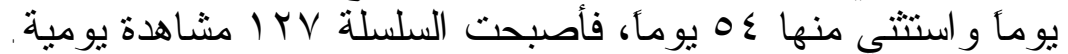

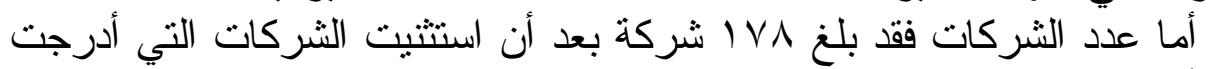

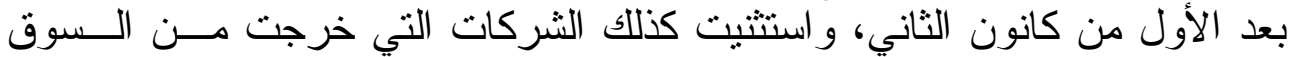

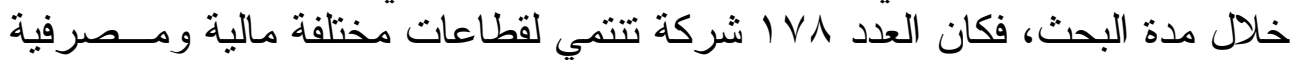

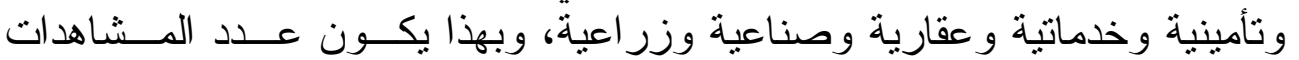

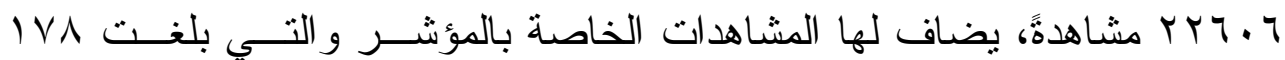

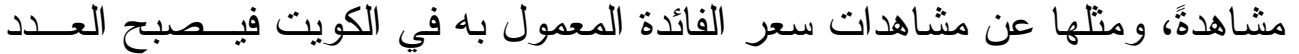

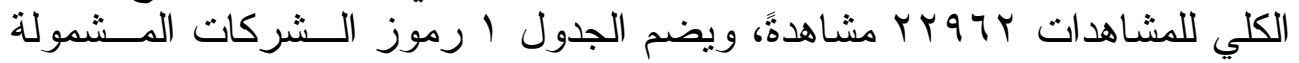
بالبحث.

خطوات تطبيق المحفظة في ضوء معطيات أنموذج تسعير الموجود الر أسمالي

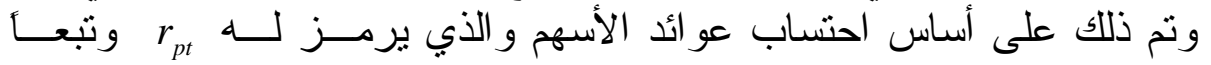
احتساب معامل بيتا من خلال المعادلة 7. $r_{p t}=\frac{\sum_{i=1}^{k} r_{i t}}{k} \ldots . .8$

ع عد الأسهم التي تتضمنها المحفظة الو احدة حيث

عداف المحافظ

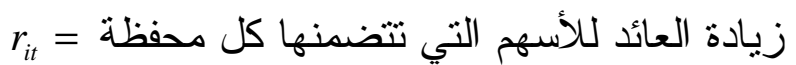

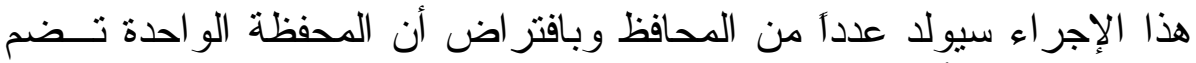

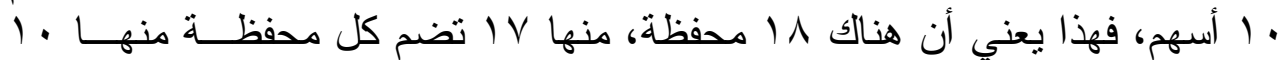




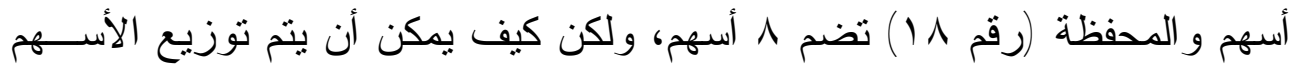

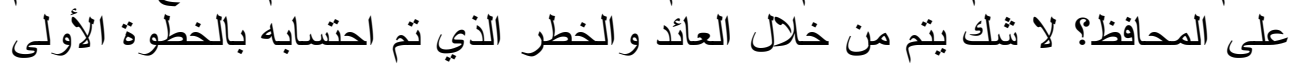

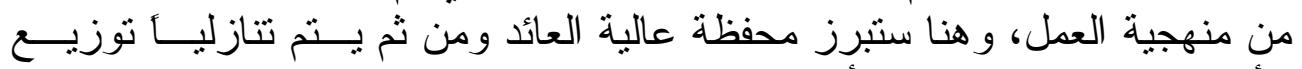

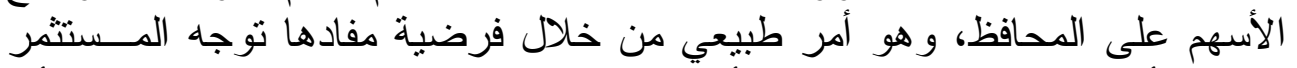

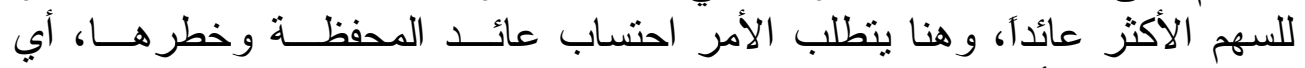
احتساب عائد الأسهم العشرة وتقائرير معامل بيتا للمحفظة. ينم تقدير بيتا للمحفظة بموجب المعادلة

$r_{p t}=a_{p}+\beta_{p} \cdot r_{m t}+e_{p t} \ldots . .9$

معدل عائد المحفظة

بيتا المحفظة ع باند المحظة

$r_{m}=$ معدل عائد السوق السوف

$a_{p}=$ معامل الفا المحفظة

بو اقي المحفظة في معادلة النموذج

نتائج البحث وتفسير الأنموذج التجن

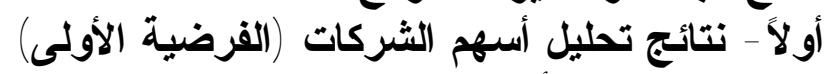

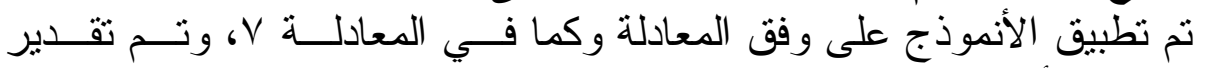

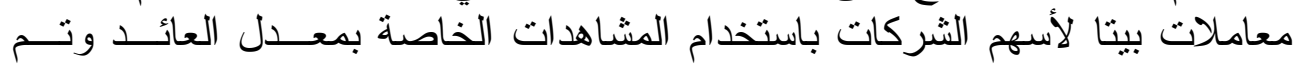

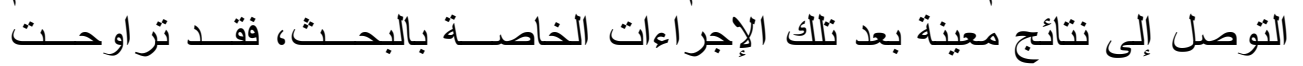

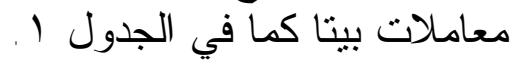

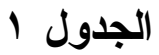

تقدير معامل بيتا لأسهم الثركات المبلة المبلة في

سوق الكويت للأور اقن المالية

\begin{tabular}{|c|c|}
\hline معامل بيتا & 101 \\
\hline 0.7793 & 102 \\
\hline 0.8200 & 103 \\
\hline 0.6799 & 104 \\
\hline 0.9678 & 105 \\
\hline 0.9414 & 106 \\
\hline 0.9959 & 107 \\
\hline 0.9413 & 108 \\
\hline 1.2462 & 109 \\
\hline 1.6521 & 201 \\
\hline 0.6255 & 202 \\
\hline 0.6228 & \\
\hline
\end{tabular}




\begin{tabular}{|c|c|}
\hline معامل بيتا & رمز الشركة \\
\hline 0.8725 & 203 \\
\hline 0.9992 & 204 \\
\hline 0.8929 & 205 \\
\hline 0.9585 & 206 \\
\hline 1.8447 & 207 \\
\hline 1.0686 & 208 \\
\hline 0.4828 & 209 \\
\hline 0.2730 & 210 \\
\hline 1.3416 & 211 \\
\hline 2.0464 & 212 \\
\hline 2.5459 & 213 \\
\hline-0.0215 & 214 \\
\hline 1.5621 & 215 \\
\hline 0.7831 & 216 \\
\hline 1.0668 & 217 \\
\hline 1.6393 & 218 \\
\hline 0.9540 & 219 \\
\hline 1.3386 & 220 \\
\hline 0.5073 & 221 \\
\hline 1.5035 & 222 \\
\hline 2.3250 & 223 \\
\hline 1.0405 & 224 \\
\hline 0.3206 & 225 \\
\hline 0.6752 & 226 \\
\hline 1.0200 & 227 \\
\hline 1.8317 & 228 \\
\hline 0.6425 & 229 \\
\hline-0.3172 & 230 \\
\hline 0.5616 & 231 \\
\hline 1.0354 & 232 \\
\hline 0.0671 & 233 \\
\hline 1.8171 & 234 \\
\hline 0.8527 & 235 \\
\hline 0.032 & 236 \\
\hline 1.0676 & 237 \\
\hline 0.3908 & 238 \\
\hline 2.0591 & 239 \\
\hline 0.9223 & 240 \\
\hline 2.0591 & 241 \\
\hline 1.3107 & 242 \\
\hline 0.7587 & 243 \\
\hline 0.4988 & 301 \\
\hline 0.3581 & 302 \\
\hline
\end{tabular}


الدكتور الجميل [rדr]

\begin{tabular}{|c|c|}
\hline معامل بيتا & رمز الشركة \\
\hline 0.4655 & 303 \\
\hline 0.0314 & 304 \\
\hline 0.4133 & 305 \\
\hline-0.0582 & 306 \\
\hline-0.3098 & 307 \\
\hline 1.5437 & 401 \\
\hline 1.0114 & 402 \\
\hline 2.0985 & 403 \\
\hline 2.243 & 404 \\
\hline 0.7750 & 405 \\
\hline 1.4605 & 406 \\
\hline 1.9003 & 407 \\
\hline 0.5629 & 408 \\
\hline 0.5629 & 409 \\
\hline 1.2718 & 410 \\
\hline 0.5844 & 411 \\
\hline 0.1982 & 412 \\
\hline 1.3120 & 413 \\
\hline 0.7026 & 414 \\
\hline 1.5800 & 415 \\
\hline 0.6609 & 416 \\
\hline 1.7614 & 417 \\
\hline 0.3922 & 418 \\
\hline-0.4501 & 419 \\
\hline 0.6810 & 420 \\
\hline 1.1712 & 421 \\
\hline 0.2629 & 422 \\
\hline 1.4171 & 423 \\
\hline 0.7154 & 424 \\
\hline 1.0344 & 425 \\
\hline 0.7065 & 426 \\
\hline 0.5039 & 427 \\
\hline 0.7010 & 428 \\
\hline 1.0746 & 429 \\
\hline 12.597 & 501 \\
\hline-3.358 & 502 \\
\hline 4.891 & 503 \\
\hline-3.049 & 504 \\
\hline 11.467 & 505 \\
\hline-18.20 & 506 \\
\hline 3.859 & 507 \\
\hline 2.051 & 508 \\
\hline-10.476 & 509 \\
\hline 2.976 & 510 \\
\hline
\end{tabular}




\begin{tabular}{|c|c|}
\hline معامل بيتا & رمز الشركة \\
\hline 3.762 & 511 \\
\hline-5.261 & 512 \\
\hline 0.5547 & 513 \\
\hline 4.609 & 514 \\
\hline-0.9157 & 515 \\
\hline 0.2416 & 516 \\
\hline-0.3620 & 517 \\
\hline 0.3188 & 518 \\
\hline-0.116 & 519 \\
\hline 0.4256 & 520 \\
\hline 0.3107 & 521 \\
\hline 1.664 & 522 \\
\hline 1.6237 & 523 \\
\hline 0.631 & 524 \\
\hline 0.0145 & 525 \\
\hline 0.109 & 601 \\
\hline-2.737 & 602 \\
\hline 17.32 & 603 \\
\hline-12.456 & 604 \\
\hline 19.88 & 605 \\
\hline-39.96 & 606 \\
\hline 1.582 & 607 \\
\hline 0.2750 & 608 \\
\hline 0.047 & 609 \\
\hline 3.4703 & 610 \\
\hline 1.782 & 611 \\
\hline 2.341 & 612 \\
\hline 4.556 & 613 \\
\hline-4.802 & 614 \\
\hline-14.625 & 615 \\
\hline 1.314 & 616 \\
\hline-0.9411 & 617 \\
\hline-0.458 & 618 \\
\hline-0.3866 & 619 \\
\hline-0.2679 & 620 \\
\hline-0.3133 & 621 \\
\hline-4.456 & 622 \\
\hline 2.933 & 623 \\
\hline 0.6246 & 624 \\
\hline-0.592 & 625 \\
\hline-0.3183 & 626 \\
\hline 0.1633 & 627 \\
\hline 0.4130 & 628 \\
\hline
\end{tabular}


الدكتور الجميل [ryo]

\begin{tabular}{|c|c|}
\hline معامل بيتا & رمز الشركة \\
\hline 3.027 & 629 \\
\hline-3.334 & 630 \\
\hline 3.169 & 631 \\
\hline-7.382 & 632 \\
\hline 16.53 & 633 \\
\hline 0.488 & 634 \\
\hline 2.602 & 635 \\
\hline-8.436 & 636 \\
\hline-0.905 & 637 \\
\hline 0.4019 & 638 \\
\hline 3.018 & 639 \\
\hline-0.413 & 640 \\
\hline 1.924 & 641 \\
\hline-6.630 & 642 \\
\hline 0.5072 & 643 \\
\hline 1.9813 & 644 \\
\hline-3.630 & 645 \\
\hline 0.5265 & 701 \\
\hline 3.3172 & 702 \\
\hline 1.3805 & 703 \\
\hline 0.2685 & 704 \\
\hline 0.0812 & 705 \\
\hline-0.0748 & 803 \\
\hline 0.3247 & 804 \\
\hline 1.9082 & 805 \\
\hline 1.6330 & 806 \\
\hline 1.430 & 807 \\
\hline 1.5043 & 808 \\
\hline-0.2090 & 809 \\
\hline 1.9233 & 810 \\
\hline 1.4420 & 811 \\
\hline 0.2623 & 812 \\
\hline 0.8524 & 813 \\
\hline 0.1827 & 814 \\
\hline 0.7675 & 815 \\
\hline 0.2190 & 819 \\
\hline
\end{tabular}

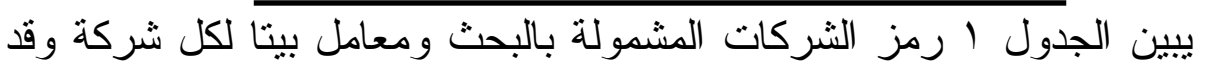

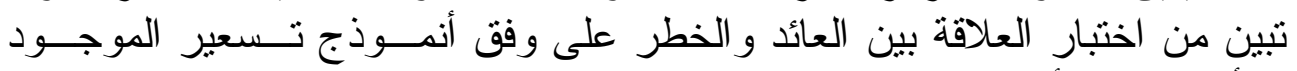

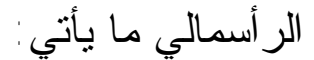

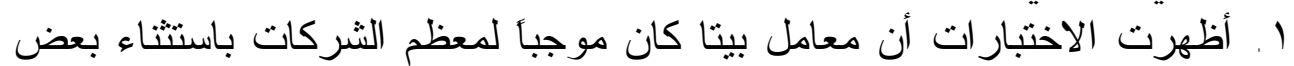
الثركات فقد كان معامل بيتا فيها سالبأ؛ مما يؤشر سلبية العلاقة، أبي أن اتجاه 


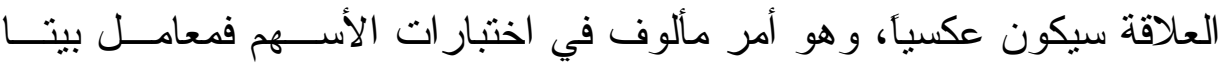

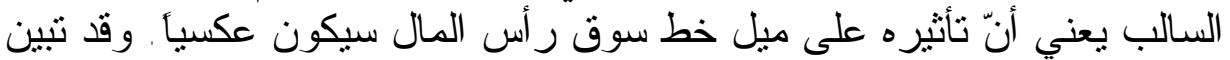

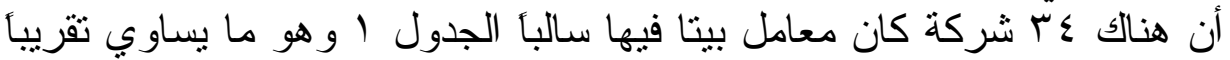

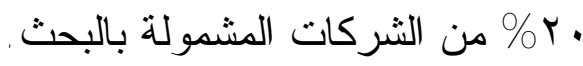

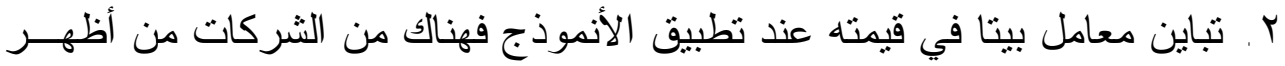

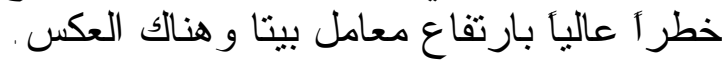

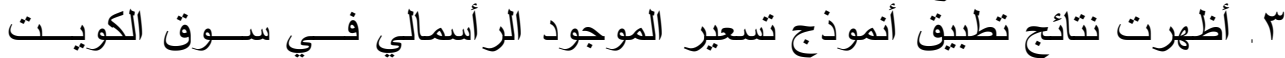

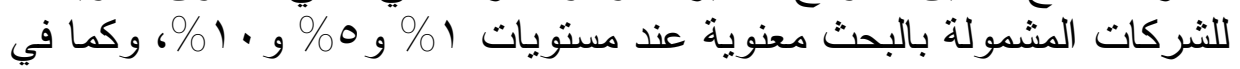

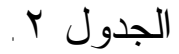

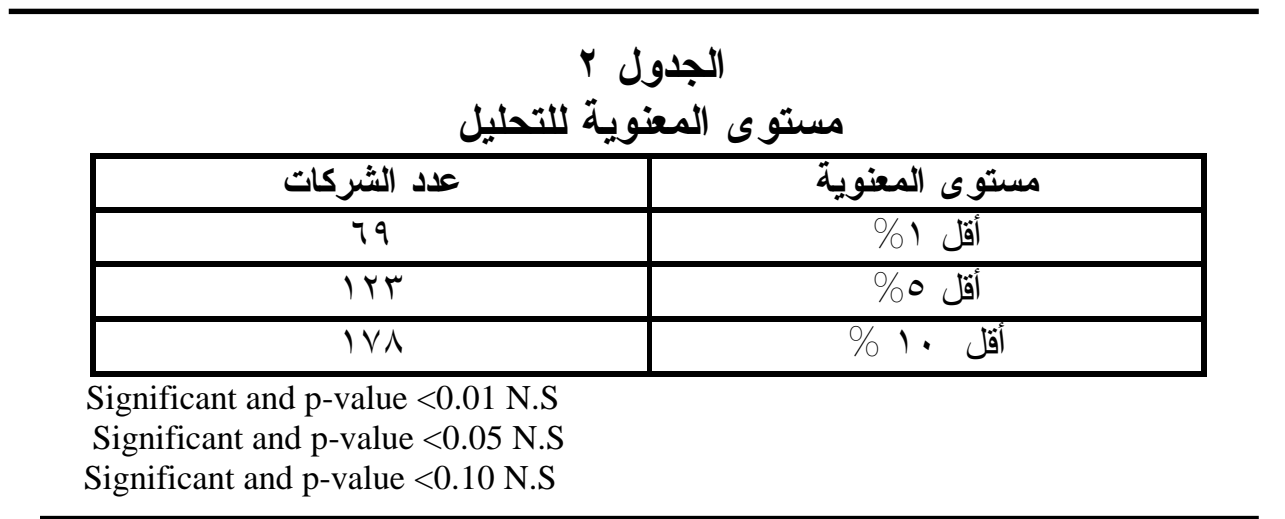

ع ـ أثتتت الاختبار ات فرضية البحث فيما يخص أسهم الثركات ؛ فقد اتخذت العلاقة

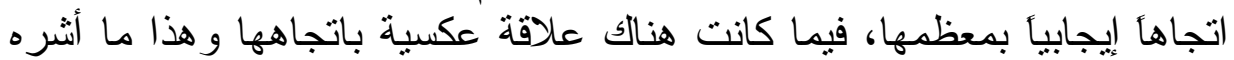

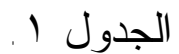

\section{ثانياً - نتائج تحليل المحفظة}

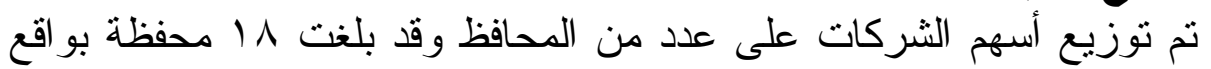

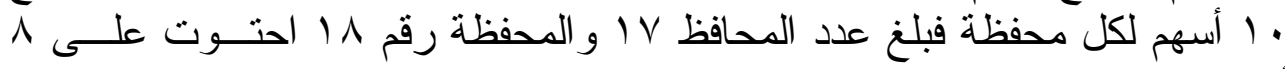
أسهم فقط. اعتمد الترتيب التنازلي لمعامل بيتا لأسهم الثركات، وتم التحليل لكل محفظة 


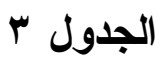

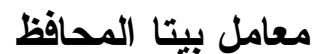

\begin{tabular}{|c|c|c|c|}
\hline رقم المحفظة & $\begin{array}{c}\text { Beta } \\
\text { معامل بيتا }\end{array}$ & $\begin{array}{l}R^{2} \\
\%\end{array}$ & $\bar{F}$ test \\
\hline$\overline{\mathrm{P} 1}$ & 9.946 & 2 & 2.5 \\
\hline $\mathrm{P} 2$ & 2.94 & 5.1 & 6.48 \\
\hline P3 & 1.671 & 19 & 28.36 \\
\hline P4 & 1.6051 & 22 & 35.96 \\
\hline P5 & 1.5435 & 31 & 54.97 \\
\hline P6 & 1.2976 & 12 & 16.60 \\
\hline $\mathrm{P7}$ & 0.9082 & 20 & 30 \\
\hline P8 & 0.9446 & 25 & 41 \\
\hline P9 & 0.8775 & 23 & 34.65 \\
\hline $\mathrm{P} 10$ & 0.6624 & 9 & 11.96 \\
\hline P11 & 0.5862 & 14 & 19.89 \\
\hline P12 & 0.505 & 8 & 9.7 \\
\hline P13 & 0.2975 & 3 & 3.48 \\
\hline P14 & 0.3178 & 2 & 2.14 \\
\hline P15 & -0.132 & 2 & 1.67 \\
\hline P16 & -0.481 & 3 & 3.53 \\
\hline P17 & -3.82 & 2 & 2.2 \\
\hline P18 & -15.93 & 2 & 2.3 \\
\hline
\end{tabular}

$$
\text { يتبين من الجدول r ما يأتي: }
$$

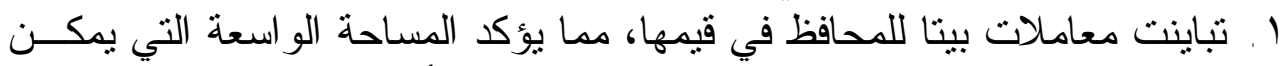

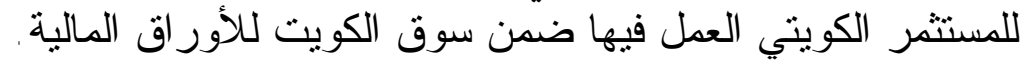

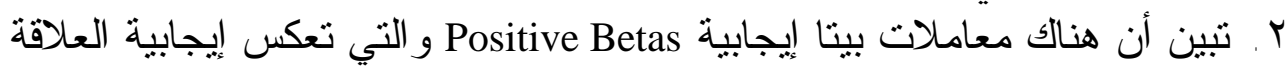

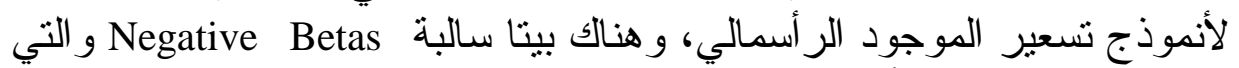

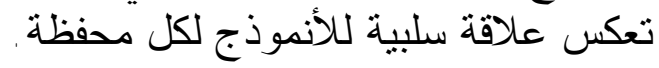

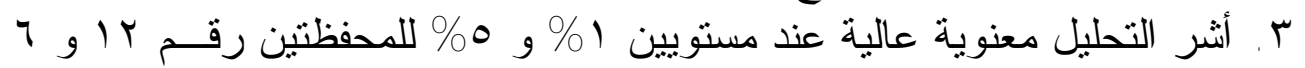

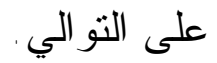

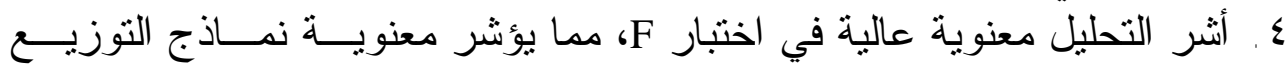

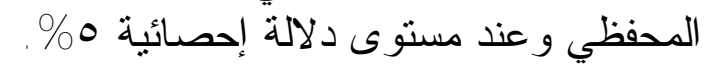

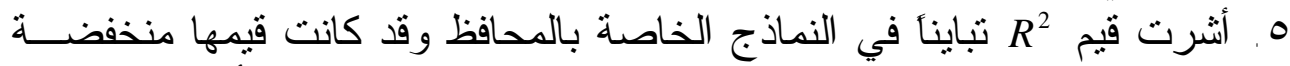

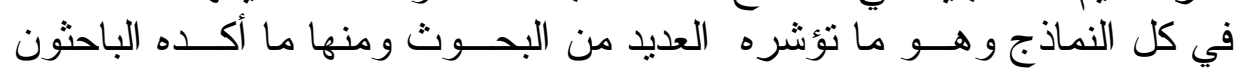
Grigoris Michailidis, Stavros Tsopoglou, Demetrios Papanastasiou and .Eleni Mariola 2006.

ثالثاً - نتائج تحليل السوق (بيتا السوق) كانت نتائج التحليل كما في الجدول عـ ـ النوف) 


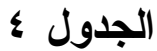

معامل بيتا لسوق الكويت للأوراق المالية

\begin{tabular}{|c|c|c|}
\hline B & T-calculate & P-value \\
\hline معامل & & \\
\hline $0.93524^{*}$ & 19.88 & 0.000 \\
\hline
\end{tabular}

$=$ Significant and p-value $<0.05$ N.S

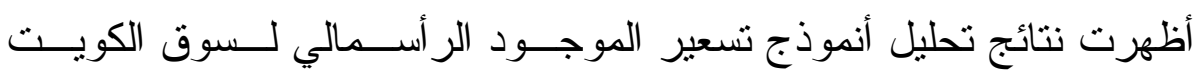

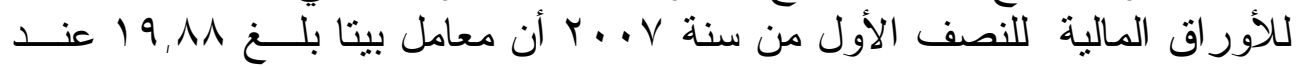

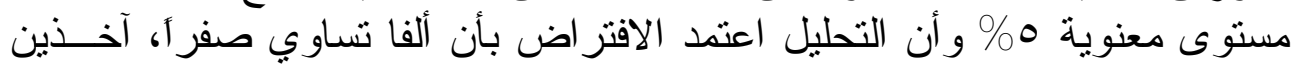

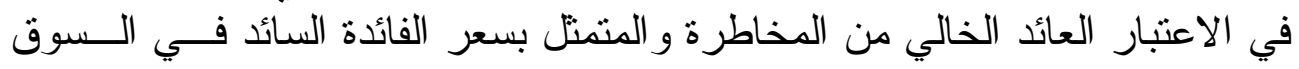

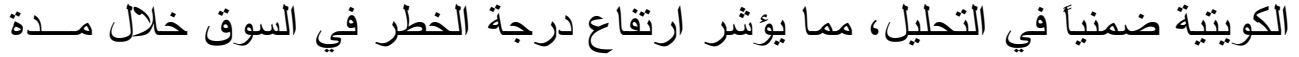

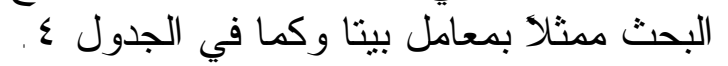

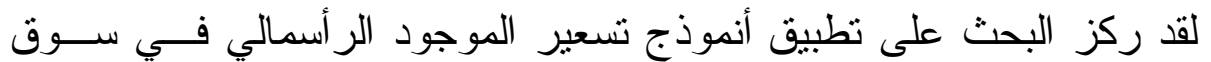

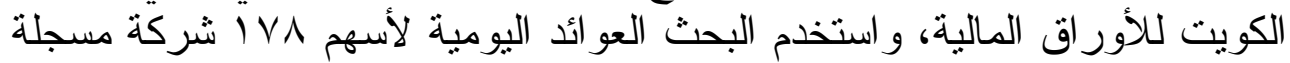

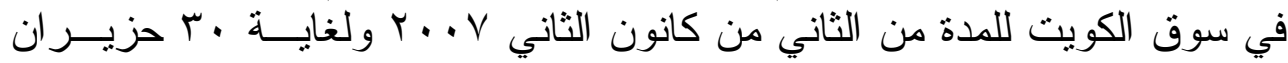
r...

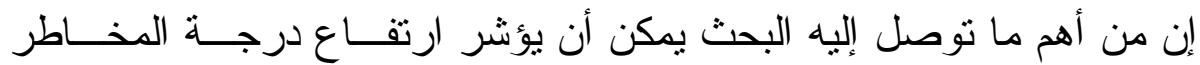

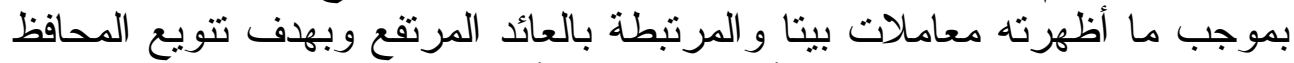

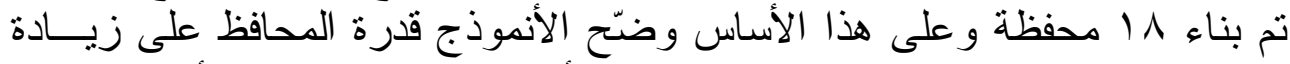

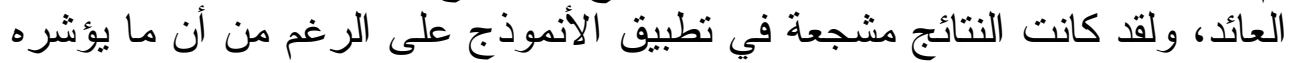

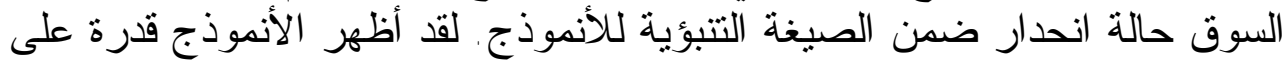

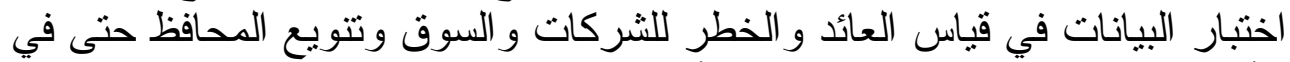

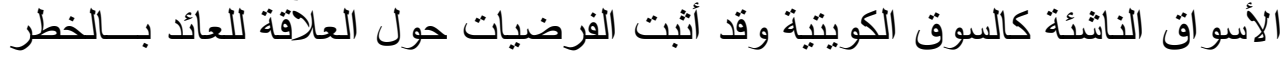

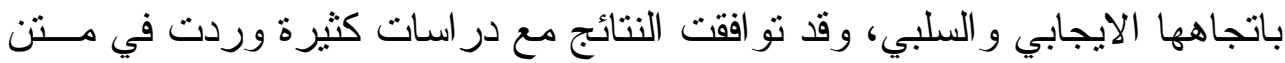

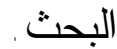
إن المضامين الدقيقة لمعامل بيتا في اختبار ثنائية العائد و الخطر و العلاقة بين

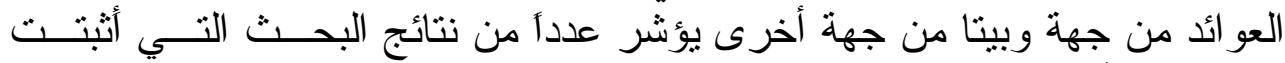

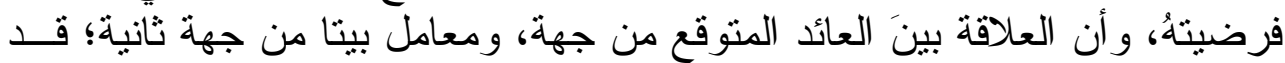

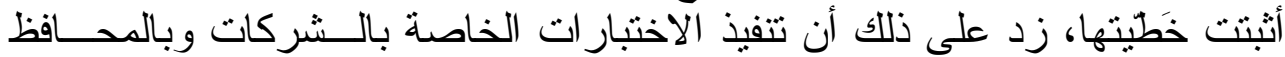

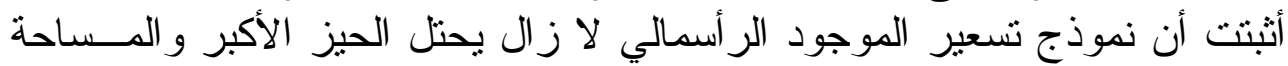



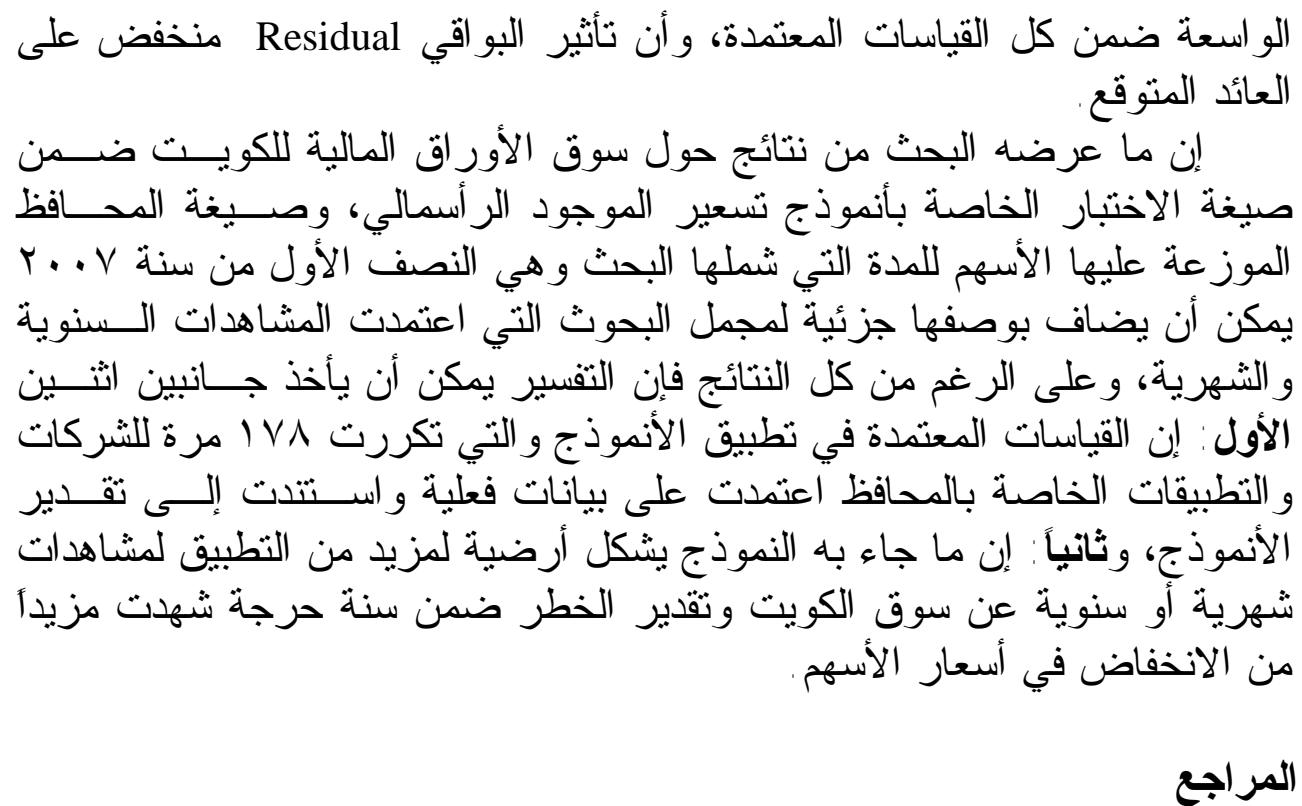

1. Andre F. perold, 2004, The Capital Asset Pricing Model, Journal of Economic perspectives, Volume 18, Number 3 - Summer .

2. Basu Sangoy, 1977, Investment performance of common stocks in relation to their price-earning ratios, Journal of Finance 32.

3. Bekaet, G.,Harvey ,C., 1997, Emerging equity market volatility, Journal of Financial Economics 43.

4. Bill Rees, 1990, Financial Analysis, Prentice Hall, .

5. Bodie, Kane \& Marcus, 1999, Investment, McGraw -Hill,.

6. Buckley, Ross, 1998, Westerfield and Jaffe, Corporate Finance Europe, McGraw Hill.

7. ChanL., Hamao Y., Lakonishok J., 1991, Fundamentals and stock returns in Japan, Journal of Finance 46.

8. Chatterjee, Sayan ; Lubatkin, Michael H., 1999; Schuize, William, Toward a strategic theory of risk premium ; moving beyond CAPM (capital asset pricing model) Academy of Management Review, July.

9. Chin, Shimin; Dodd, James L, 2002, Market efficiency, CAPM, and value - relevance of earning and EVA: A reply to the comment by professor Paulo, Journal of Management Issues Dec..

10. Chou ; Pin - Huang,. 2000, Alternative Tests of The Zero - Beta CAPM, Journal of Financial Research Dec.

11. Conway L.Lackman, 1996, Exchange Risk: Acapital Asset Pricing Model Framework, Journal Of Financial And Strategic Decisions, Volume 9 Number 1, Spring .

12. David W. Mullins, Jr, Does 1982, the Capital Asset Pricing Model Work ? Harvard Business Review m Jan - Feb .

13. Faff, Robert. 2001. Amulivariate test of a dual - beta CAPM: Austral ( capital asset pricing model ), The Financial Revirw Nov.

14. Denzil Waston \& Anthony Head, 2001, Corporate Finance Principle \& Practice, Prentice Hall,.

15. Fama EF and French, 1992, The cross- section of expected stock returns Journal of Finance: 47. 
16. Fama, E and French, 1993, Common risk factors in the returns on stocks and bondsm Gournal of Financial Economics ,33.

17. Gitman, Lawrence J, 2001, Principle of Managerial Finance, Addison-Wesley.

18. Grigoris Michailidis, 2006, Stavros Tsopoglou, Demetrios Papanastasiou and Eleni Mariola, Testing the Capital Asset Pricing Model (CAPM): The Case of the Emerging Greek Securities Market, International Research Journal of Finance and Economics, 4.

19. John Graham, Cambell R. Harvey, 2001, The theory and practice of corporate finance: evidence from the field, Journal of Financial Economics: 60.

20. Mark Granblatt \& Sheridan, 1998 Titman m Financial Markets and Corporate Strategy, McGraw-Hill.

21. Martin Lally, Tony van Zijl, 2003, Capital gain tax and the capital asset pricing model, Accounting and Finance 43.

22. Nick Durack, Robert B.Durand, Ross A. Maller, 2004, Abest choice among asset capital models? The conditional Capital Asset Pricing Model in Australia, Accounting and Finance 44.

23. Stephen A. Ross, Randolph W. Wester and Bradford D.Jordan, 1993, Fundamentals of Corporate Finance, IRWIN. 